\title{
Assessment of HY-2A GM data by deriving the gravity field and bathymetry over the Gulf of Guinea
}

\author{
Xiaoyun Wan ${ }^{1,2}$, Richard Fiifi Annan ${ }^{1 *}$ (ID and Wenbin Wang ${ }^{2}$
}

\begin{abstract}
Nine cycles of Haiyang-2A (HY-2A) IGDR (Interim Geophysical Data Record) data are used to derive gravity products over the Gulf of Guinea $\left(15^{\circ} \mathrm{W}-5^{\circ} \mathrm{E}, 4^{\circ} \mathrm{S}-4^{\circ} \mathrm{N}\right)$. Firstly, the sea surface heights $(\mathrm{SSH})$ and vertical deflections are derived and their precisions are evaluated. The comparison results show that the east component of vertical deflections has a poorer precision than the north component by 4.15 times. A theoretical proof was given to explain this point according to the error propagation rule. Gravity anomalies are then derived from vertical deflections using the removerestore method. The precision of the derived HY-2A gravity anomalies is evaluated with SIO, DTU13, EGM2008, EIGEN$6 \mathrm{C} 4$ products. The results showed that the differences between $\mathrm{HY}$-2A-derived gravity anomalies and these models have mean values larger than $0.5 \mathrm{mGal}$ and std values around 7.0-7.3 mGal. In order to improve the precision, an improved new version of gravity anomalies was derived by assigning a small weight to the east component of vertical deflections, since the precision of which is poorer than the north component. Comparison with the initial model showed that the precision of the new gravity anomalies is an improvement of the initial model by approximately two times. When compared with EGM2008, EIGEN-6C4, SIOv28 and DTU13, the mean values of the differences are close to zero and standard deviation of the differences are around 2.7-3.0 mGal. The improved gravity anomalies were used to invert the bathymetry of the region using the gravity-geologic method. The modeled bathymetry compared well with a previous bathymetric study by the authors that used DTU13 gravity anomalies. It also performed well against ETOPO1 and SRTM15+V2; with difference means, standard deviations and correlation coefficients of $26.67 \mathrm{~m}$, $183.09 \mathrm{~m}, 0.9562$; and $12.26 \mathrm{~m}, 174.55 \mathrm{~m}, 0.9590$, respectively. This implies that SSH data from HY-2A are geophysically reliable; and hence, can be incorporated with SSH data from other satellite altimeters.
\end{abstract}

Keywords: Gravity anomaly, Vertical deflection, Bathymetry, Haiyang-2A, Sea surface height, Gulf of Guinea

\section{Introduction}

Marine gravity anomaly is one of the most fundamental quantities in the geo-related industries and for research in the Earth sciences. It is the anomaly in gravity over the oceans, measured on the geoid-the equipotential surface-and the theoretical gravity measured on a reference ellipsoid. It has various applications, such as: being a tool for exploration of energy resources (Becker et al.

\footnotetext{
*Correspondence: richannan@outlook.com

${ }^{1}$ School of Land Science and Technology, China University

of Geosciences (Beijing), Beijing 100083, China

Full list of author information is available at the end of the article
}

2009), for modeling marine geoid (Soltanpour et al. 2007; Chander and Majumdar, 2016), a medium for enhancing bathymetric models (Hsiao et al 2016; Sandwell et al. 2001; Hwang and Chang 2014), as well as for delineating continent-ocean boundaries (Sandwell et al. 2013). The traditional means of acquiring marine gravity anomaly data is by using gravimeters onboard ships; however, this process is very expensive and is mostly restricted to regional maritime boundaries.

Satellite altimetry, a space technology developed by the National Aeronautics and Space Administration (NASA) about four decades ago, is a remote sensing technique of measuring heights of the Earth's surface (preferably 
the ocean surfaces) relative to an ellipsoidal surface. Due to the variety of its applications, various countries and economic blocs have launched their respective altimeter satellites, which has since 1991 provided the geoscience community with significant volume of sea surface height (SSH) data. The SSH data are then used to recover marine gravity anomalies (Andersen and Knudsen 1998; Hwang 1998; Soltanpour et al. 2007; Dadzie et al. 2008; Sandwell et al. 2014, 2019; Zhang et al. 2016). Comparatively, satellite altimetry is less time-consuming; and has been proven by Sandwell et al. (2013) to yield comparable marine gravity models to existing governmental shipborne gravity data.

This increase in data quantity and quality has definitely led to researchers to model the marine gravity anomalies of their respective countries' maritime waters. For instance: Soltanpour et al. (2007) modeled the gravity field of Norway's maritime waters using data from ERS-1, ERS-2 and ENVISAT satellites. Dadzie et al. (2008) used combined data to derive a $2.5^{\prime} \times 2.5^{\prime}$ gravity field of the south China and Philippine seas. Recently, Zhang et al. (2016) and Zhu et al. (2020) have separately constructed $1^{\prime} \times 1^{\prime}$ marine gravity models over the south China seas.

Even though the proliferation of satellite altimetry data has led to improved regional marine gravity models of various countries and economic blocs, this is yet to be realized for the waters of West Africa. The marine waters of West Africa are not extensively studied, even though the region harbors a significant $5 \%$ of the world's oil reserves (Osaretin 2011; Weszkanys 2011). It is well known that ocean surface activities have submarine origins caused by crustal mass variations which are best revealed by gravity anomalies. This, coupled with the region's varying seafloor topography as shown by Annan and Wan (2020), makes it imperative to investigate the marine gravity field in the region. The present study does this investigation by taking advantage of SSH data from the geodetic phase of China's Haiyang-2A (HY-2A) satellite.

The HY-2A satellite, launched in 2011, is the first Chinese altimetry satellite designed for ocean dynamic and environmental parameters detection. In order to achieve its goal, the main payloads of HY-2A include a dual-frequency radar altimeter for providing sea surface height observations, a microwave scatterometer for marine wind detection, a scanning microwave radiometer for detecting sea surface temperature, wind speed, water vapor; a calibration microwave radiometer for wet tropospheric path delay correction (Jiang et al. 2018), and a Global Positioning System (GPS) receiver for satellite orbit determination. The satellite has an inclination of $99.34^{\circ}$ and operates with a 14-day repeat period for physical oceanography studies and then with a 168-repeat period for geodetic studies (referred here as HY-2A/GM) since March 2016 (Jiang et al. 2018). Though there have been studies which discussed the reliability of data from its geodetic mission, these studies are very few and were conducted in the South China Sea. For instance: Zhang et al (2020) modeled a $1^{\prime} \times 1^{\prime}$ marine gravity field of the South China Sea by incorporating HY-2A geodetic mission data with other satellites' data. Another study over the South China Sea by Zhu et al (2019) concluded that marine gravity derived from HY-2A is comparable to those derived from similar $\mathrm{Ku}$-band satellite altimeters. Zhu et al (2020) also developed SCSGA (South China Sea Gravity Anomaly) version 1.0, which incorporated HY-2A/GM with other satellites.

There are two main methods of inverting marine gravity anomalies from SSH data. The first method computes gravity anomalies through geoidal heights by using the inverse Stokes' formula solved by Fast Fourier Transform (FFT) or least squares collocation (LSC). This method has the weakness of being sensitive to cross-track gradients from sea surface variability resulting in the diminishing of distance between parallel tracks (Olgiati et al. 1995; Andersen and Knudsen 1998). The second approach converts deflections of the vertical derived from geoid gradients, to gravity anomalies via the inverse Vening Meinesz formula or Sandwell's method (Sandwell and Smith, 1997). This approach is also solvable by FFT or LSC.

The present study assesses the reliability and geophysical capabilities of SSH data from HY-2A/GM over the Gulf of Guinea by deriving a marine gravity field for the region. The derived marine gravity field is further used to predict the bathymetry of the region using the gravity-geologic method (GGM). Through this, a regional marine gravity model is derived for the region and the performance of HY-2A/GM is assessed in another environment with significant mass variations apart from the South China Sea, where almost all the regional evaluations of $\mathrm{HY}-2 \mathrm{~A}$ performance have been carried out.

\section{Data source and study area}

All the available data of HY-2A, provided by National Satellite Ocean Administration Service of China (ftp2.nsoas. org.cn), are used in this research, i.e., 1-9 cycles of IGDR (Interim Geophysical Data Record) data (Yang et al. 2016). The time period is from March 30, 2016 to April 30, 2020. Using geophysical correction constraints compiled in Table 1, the IGDR data are used to compute SSH according to Eq. (1):

$$
\mathrm{SSH}=\text { orbit }- \text { range }-\sum \text { corrections, }
$$


Table 1 Constraints on geophysical corrections (unit: $\mathbf{m}$ )

\begin{tabular}{ll}
\hline Correction due to & Constraint \\
\hline Dry troposphere & $-2.5 \sim-1.9$ \\
Wet troposphere & $-0.5 \sim 0.001$ \\
lonosphere & $-0.4 \sim 0.04$ \\
Sea state bias & $-0.5 \sim 0$ \\
Solid earth tide & $-1 \sim 1$ \\
Pole tide & $-5 \sim 5$ \\
Ocean tide & $-5 \sim 5$ \\
Inverse barometric effect & $-2 \sim 2$ \\
\hline
\end{tabular}

where $\quad \sum$ corrections $=\sum$ corrections due to. $\left(\begin{array}{ll}\text { dry troposphere, } & \text { solid earth tide, } \\ \text { wet troposphere, } & \text { pole tide, } \\ \text { ionosphere, } & \text { ocean tide, } \\ \text { sea state bias, } & \text { inverse barometric effect }\end{array}\right)$.

A crossover analysis is then performed on the obtained $\mathrm{SSH}$. Figure 1 is a map of study area which covers longitude $15^{\circ} \mathrm{W}$ to $5^{\circ} \mathrm{E}$, and from latitude $4^{\circ} \mathrm{S}$ to $4^{\circ} \mathrm{N}$. The region stretches from the continental shelve of Liberia in West Africa to the central African country of Gabon.

\section{Method}

\section{Computation of vertical deflections}

According to Sandwell and Smith (1997), vertical deflections can be derived from the following equations. Firstly, using the observations of altimetry satellite, the geoid difference values along the satellite orbit can be obtained by Eq. (2):

$$
\left\{\begin{array}{c}
\Delta N_{\mathrm{a}}=\frac{\partial N}{\partial \theta} \Delta \theta_{\mathrm{a}}+\frac{\partial N}{\partial \lambda} \Delta \lambda_{\mathrm{a}} \\
\Delta N_{\mathrm{d}}=\frac{\partial N}{\partial \theta} \Delta \theta_{\mathrm{d}}+\frac{\partial N}{\partial \lambda} \Delta \lambda_{\mathrm{d}}
\end{array}\right.
$$

where $\Delta \theta_{\mathrm{a}}$ and $\Delta \theta_{\mathrm{d}}$ mean the co-latitude variation values along the ascending and descending orbits, respectively; $\Delta \lambda_{\mathrm{a}}$ and $\Delta \lambda_{\mathrm{d}}$ mean the longitude variation values along the ascending and descending orbits, respectively; $N$ denotes geoid heights; $\Delta N_{\mathrm{a}}$ and $\Delta N_{\mathrm{d}}$ mean the geoid height variation values along the ascending and descending orbits. As long as $\frac{\partial N}{\partial \theta}$ are $\frac{\partial N}{\partial \lambda}$ obtained, the two components of vertical deflections can be easily derived as,

$$
\left\{\begin{array}{l}
\varepsilon=\frac{\partial N}{r \partial \theta} \\
\eta=-\frac{\partial N}{r \sin \theta \partial \lambda}
\end{array},\right.
$$

where $r$ is the radius of the Earth; $\varepsilon$ and $\eta$ denote the north and east components of the vertical deflections. In

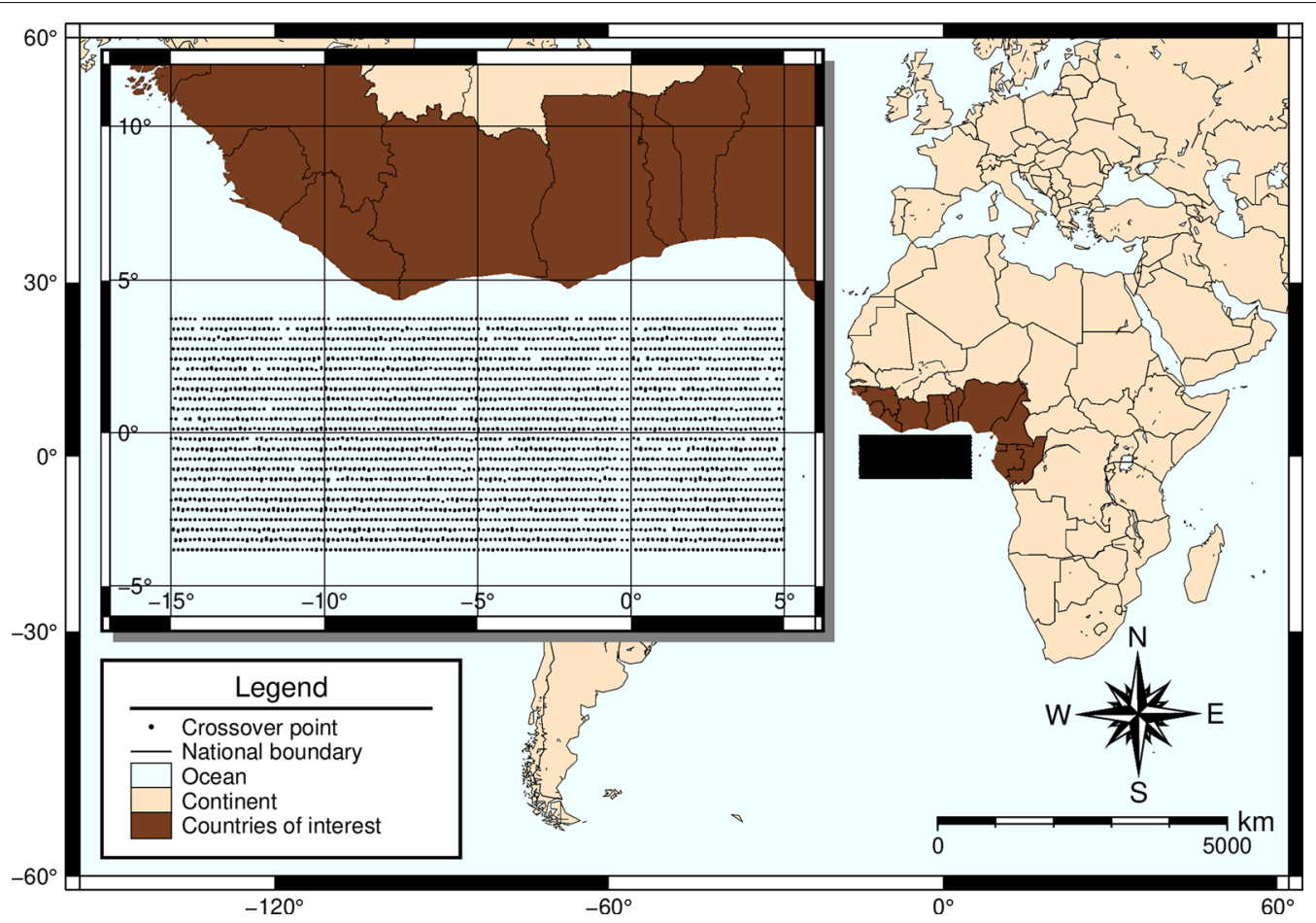

Fig. 1 Map of the study area 
order to analyze the accuracy of vertical defection, Eq. (4) is derived from Eq. (2):

$$
\left\{\begin{array}{l}
\frac{\partial N}{\partial \theta}=\frac{\Delta N_{\mathrm{a}} \Delta \lambda_{\mathrm{d}}-\Delta N_{\mathrm{d}} \Delta \lambda_{\mathrm{a}}}{\Delta \theta_{\mathrm{a}} \Delta \lambda_{\mathrm{d}}-\Delta \theta_{\mathrm{d}} \Delta \lambda_{\mathrm{a}}} \\
\frac{\partial N}{\partial \lambda}=\frac{\Delta N_{\mathrm{a}} \Delta \theta_{\mathrm{d}}-\Delta N_{\mathrm{d}} \Delta \theta_{\mathrm{a}}}{\Delta \lambda_{\mathrm{a}} \Delta \theta_{\mathrm{d}}-\Delta \lambda_{\mathrm{d}} \Delta \theta_{\mathrm{a}}}
\end{array}\right.
$$

By setting $\Delta \theta_{\mathrm{a}} \approx-\Delta \theta_{\mathrm{d}}=\Delta \theta, \Delta \lambda_{\mathrm{a}} \approx \Delta \lambda_{\mathrm{d}}=\Delta \lambda$, this formula can be simplified as:

$$
\left\{\begin{array}{l}
\frac{\partial N}{\partial \theta}=\frac{\Delta N_{\mathrm{a}}-\Delta N_{\mathrm{d}}}{2 \Delta \theta} \\
\frac{\partial N}{\partial \lambda}=\frac{\Delta N_{\mathrm{a}}-\Delta N_{\mathrm{d}}}{-2 \Delta \lambda}
\end{array} .\right.
$$

\section{Inversion of gravity anomaly}

Residual gravity anomaly, denoted as $\delta g$, can be derived from residual vertical deflections (denoted as $\Delta \varepsilon, \Delta \eta$ ) (Sandwell and Smith 1997) through Eq. (6):

$$
\delta g=\operatorname{ifft}\left(\frac{i}{|K|} \bar{\gamma}[u \Delta \varepsilon(K)+v \Delta \eta(K)]\right),
$$

where

$$
\left\{\begin{array}{l}
K=(u, v) \\
u=\frac{1}{\lambda_{x}} \\
v=\frac{1}{\lambda_{y}} \\
|K|=\sqrt{u^{2}+v^{2}}
\end{array},\right.
$$

ifft is the inverse FFT, and $\bar{\gamma}$ is the mean value of gravity. Gravity anomaly can then be recovered through the remove-restore method as summarized in Fig. 2, where the former 360 degrees and orders of EGM2008 are selected as the reference model. Indeed, some other recent gravity field models, such as XGM2019e (Zingerle et al. 2020), can also be used as the reference model for deriving gravity anomalies and may help improve the accuracy of the derived gravity anomalies, because more data are used for deriving these models than EGM2008 (Zingerle et al. 2020). However, this contribution would

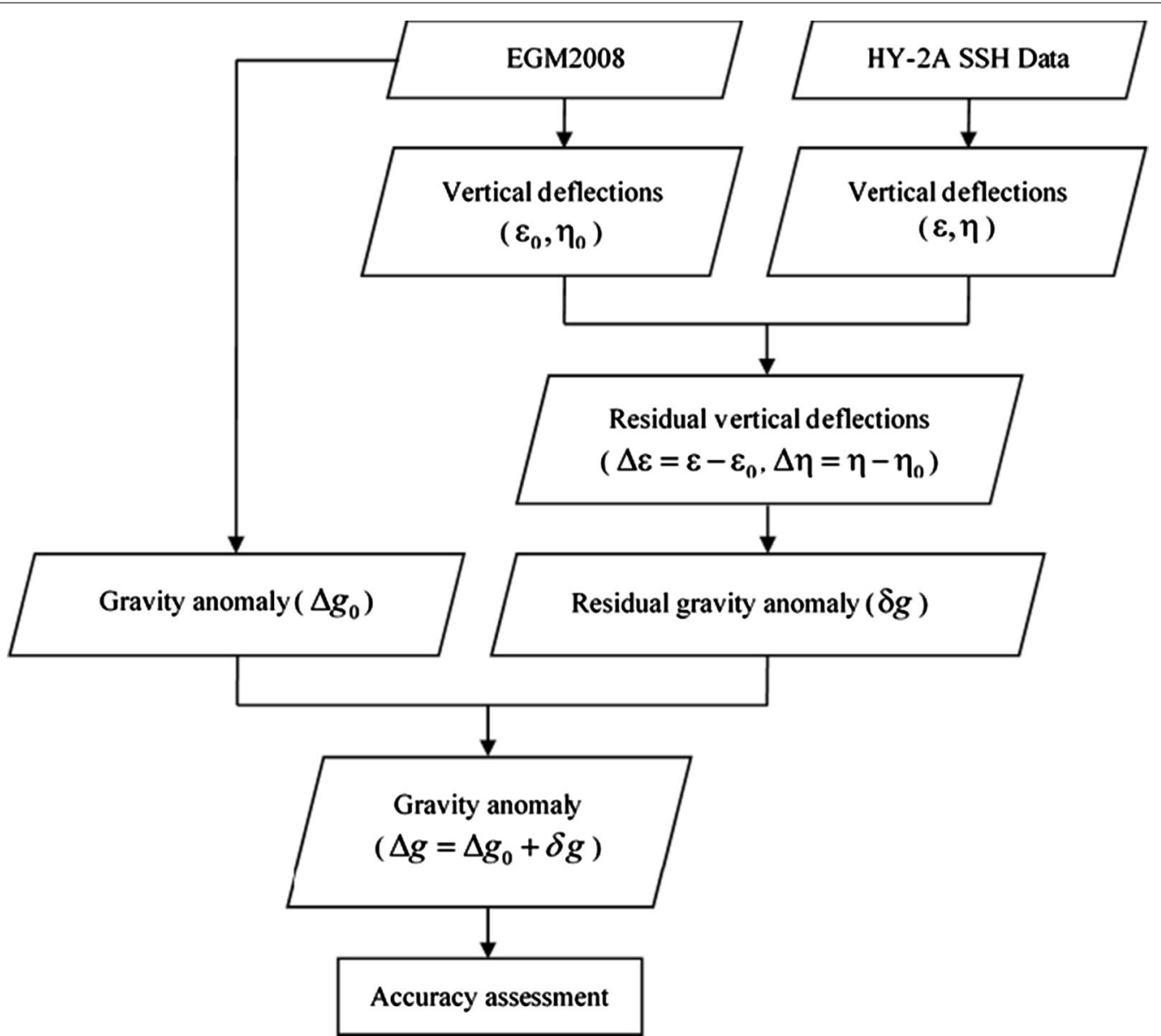

Fig. 2 Flowchart of the remove-restore procedure 
not originate from the HY-2A observations. Since the topic of this study is to assess the performance of HY-2A, we select EGM2008 as the reference model which is commonly used in most altimetry-derived gravity anomalies (Andersen et al. 2010; Sandwell et al. 2013, 2019; Andersen and Knudsen 2019; Zhu et al. 2019, 2020; Zhang et al. 2020).

\section{Results and analysis}

\section{Sea surface heights}

The crossover adjusted SSH used in this study is visualized as Fig. 3, with Fig. 3a being a 2D view. The mean sea height observed is $18.266 \mathrm{~m}$ with a standard deviation of $\pm 1.539 \mathrm{~m}$. The HY-2A-derived sea surface topography of the Gulf of Guinea is compared with DTU18 and CLS15. DTU18 is a mean sea surface model from the Technical University of Denmark, while CLS2015 is a collaborative product from Collecte Localisation Satellites (CLS) and the Centre National d'Etudes Spatiales (CNES) of France. The statistics of this comparison is summarized in Table 2. It can be seen that the sea surface topography along the northwestern continental shelves (comprising Liberia, Sierra Leone, Ivory Coast and Ghana) is relatively higher than the sea surface topography of eastern continental

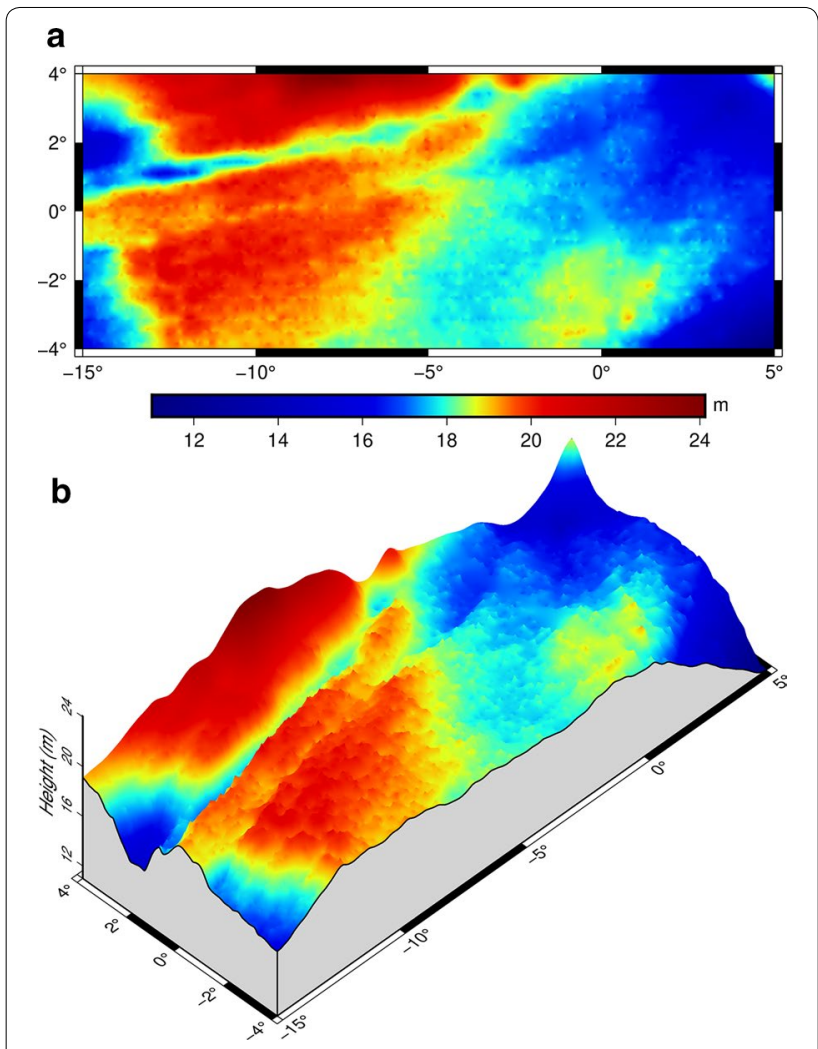

Fig. 3 SSH derived from HY-2A: a 2D view; b 3D view shelves which comprises Nigeria, Cameroon, Equatorial Guinea and Gabon. Figure 3b is a perspective view that clearly shows a narrow valley along latitude $2^{\circ} \mathrm{N}$. The crossover differences are shown in Fig. 4. The mean crossover error and its corresponding standard deviation are $-0.0095 \mathrm{~m}$ and $\pm 0.1007 \mathrm{~m}$, respectively. According to Table 2, the mean and std values of the differences between HY-2A and DTU18, CLS15 are about $-0.88 \mathrm{~m}$ and $\pm 0.13 \mathrm{~m}$, respectively. The index of mean differences is not close to zero which indicates there are systematic differences between HY-2A and DTU18 and CLS15. This means a calibration process is needed in order to obtain highly accurate HY-2A sea surface heights. The tide gauge and the GPS buoy are the most commonly used methodologies for the calibration (Chen et al. 2019). However, currently no data from the tide gauge and the GPS buoy are available in the study area. Instead, the calibration processing would be conducted in the near future. On the other hand, although systematic differences exist, the influence would be reduced during the vertical deflection computation since difference computation is conducted along the orbits. This is also the reason why we derive gravity anomalies by vertical deflections instead of by geoid height directly.

Table 2 Summary statistics of sea surface over the study area (unit: $\mathbf{m}$ )

\begin{tabular}{lcccc}
\hline SSH & Minimum & Maximum & Mean & Std \\
\hline HY-2A & 10.971 & 23.806 & 18.266 & 1.539 \\
DTU18 & 11.996 & 24.408 & 19.183 & 1.533 \\
CLS15 & 11.972 & 24.441 & 19.185 & 1.537 \\
HY-2A-DTU18 & -1.175 & -0.403 & -0.880 & 0.129 \\
HY-2A-CLS15 & -1.157 & 0.419 & -0.882 & 0.128 \\
CLS15-DTU18 & -0.095 & 0.079 & 0.002 & 0.015 \\
\hline
\end{tabular}

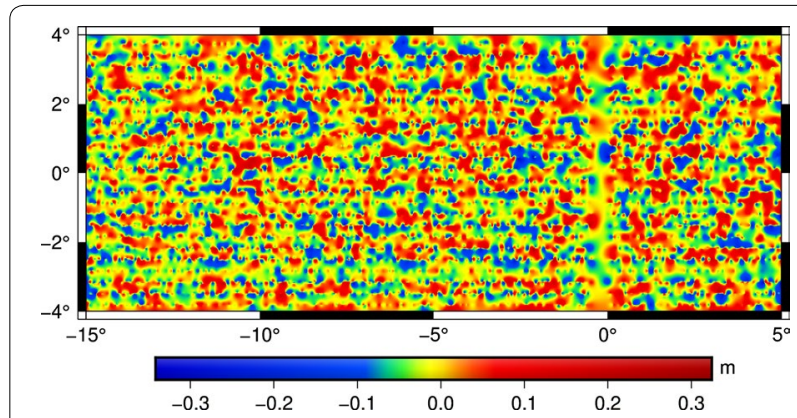

Fig. 4 Self-crossover errors of SSH 


\section{Vertical deflections}

The computed north $(\varepsilon)$ and east $(\eta)$ components of deflection of the vertical are shown as Fig. $5 \mathrm{a}$ and b, respectively. In order to validate the vertical deflection components, they are compared with simulated components from EGM2008 and EIGEN-6C4 global geopotential models. The simulation was done using



2160 degree/order of the global geopotential models. Figure 6 shows boxplots of the vertical deflection components. The boxplots analyze the dispersion of points (red crosses) around the median point (central red line). The blue box engulfing the median represents the lower and upper quartiles of each dataset; while the black lines are the whisker lines, beyond which are outlying points (red pluses) of each dataset. Similar results are seen for the north component in all three models, as shown in Fig. 6a. The statistics of the east component does not favor HY-2A, as seen in Fig. 6b. It is obvious that the accuracy of the north component is better than the accuracy of the east component. Table 3 summarizes the result of this comparison.

Indeed, the phenomenon that the accuracy of the east components of the vertical deflections is lower than that of the north component has once been pointed out by other researches, such as Sandwell and Smith (1997) and Zhang (2017). Here, the explanation for that is given via error propagation analysis. Assuming the precisions of the height observations along the ascending orbit and descending orbit are both $\delta_{\mathrm{h}}$, precisions of vertical deflections can be derived according to error propagation rule from Eqs. (3) and (5), i.e.,

$$
\left\{\begin{array}{l}
\delta_{\varepsilon}^{2}=\left(\frac{1}{r \Delta \theta}\right)^{2} \delta_{\mathrm{h}}^{2} \\
\delta_{\eta}^{2}=\left(\frac{1}{r \sin \theta \Delta \lambda}\right)^{2} \delta_{\mathrm{h}}^{2}
\end{array} .\right.
$$

And thus,
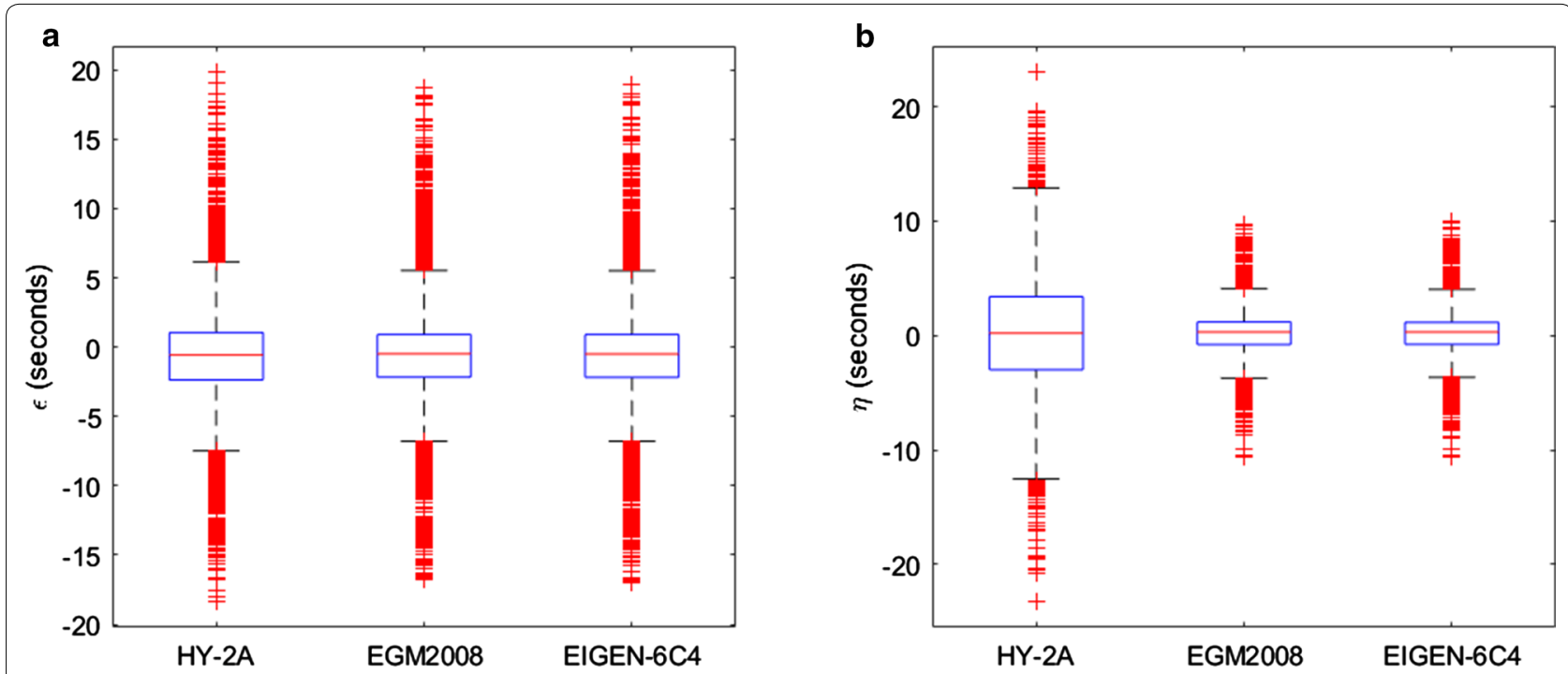

Fig. 6 Dispersions of $\mathbf{a}$ North and $\mathbf{b}$ East components of vertical deflection 
Table 3 Summary statistics of components of vertical deflection (unit: seconds)

\begin{tabular}{llllrl}
\hline Model & Component & Minimum & Maximum & Mean & Std \\
\hline HY-2A & $\varepsilon$ & -18.319 & 19.829 & -0.705 & 3.444 \\
& $\eta$ & -23.186 & 22.998 & 0.189 & 4.917 \\
EGM2008 & $\varepsilon$ & -20.496 & 20.063 & -0.685 & 3.418 \\
& $\eta$ & -13.267 & 18.225 & 0.155 & 1.849 \\
EIGEN-6C4 & $\varepsilon$ & -20.677 & 19.995 & -0.688 & 3.439 \\
& $\eta$ & -13.693 & 18.494 & 0.157 & 1.867 \\
HY-2A- & $\varepsilon$ & -6.052 & 6.195 & -0.005 & 1.099 \\
EGM2008 & $\eta$ & -22.027 & 19.471 & 0.021 & 4.568 \\
HY-2A-EIGEN- & $\varepsilon$ & -6.190 & 6.170 & -0.004 & 1.104 \\
6C4 & $\eta$ & -22.070 & 19.477 & 0.021 & 4.569 \\
EIGEN-6C4- & $\varepsilon$ & -0.738 & 0.600 & -0.002 & 0.157 \\
EGM2008 & $\eta$ & -0.701 & 0.651 & 0.001 & 0.178 \\
\hline
\end{tabular}

$$
\frac{\delta_{\eta}^{2}}{\delta_{\varepsilon}^{2}}=\frac{\Delta \theta^{2}}{\Delta \lambda^{2} \sin \theta^{2}} .
$$

Based on angular velocities of the satellite and the Earth rotation, denoted as $\omega_{\mathrm{s}}$ and $\omega_{\text {Earth }}$, respectively, we have,

$$
\left\{\begin{array}{l}
\Delta \theta=\omega_{\mathrm{s}} \cos (90-I) \Delta t \\
\Delta \lambda=\left(\omega_{\text {Earth }}-\frac{\omega_{\mathrm{s}} \sin (90-I)}{\sin \theta}\right) \Delta t
\end{array},\right.
$$

where $I$ is the orbital inclination, and $\Delta t$ is the time interval. Hence, Eq. (11) can be obtained:

$$
k=\frac{\delta_{\eta}}{\delta_{\varepsilon}}=\left|\frac{\omega_{\mathrm{s}} \cos (90-I)}{\omega_{\text {Earth }} \sin \theta-\omega_{\mathrm{s}} \sin (90-I)}\right| .
$$

Figure 7 shows the values of $k$ with different values of $\theta$ in our study area. According to this figure, the error of the east component of vertical deflections is larger than the north component by nearly 4.2 times in the study area. This conclusion is consistent with the results of Table 3, in which the error of the east component of vertical deflections is larger than the north component by 4.15 times.

\section{Gravity anomalies}

Finally, the gravity anomalies are derived according to the procedure described in Fig. 2 . The distribution of the HY2A-derived gravity anomalies is shown in Fig. 8, and the differences between them and other models are given in Table 4 . These gravity anomaly models include: DTU13, SIOv28 (Scripps Institution of Oceanography version 28 ) and simulated gravity anomalies from EGM2008 and EIGEN-6C4.

According to Table 4, the differences between HY-2A-derived gravity anomalies and SIO, DTU13,

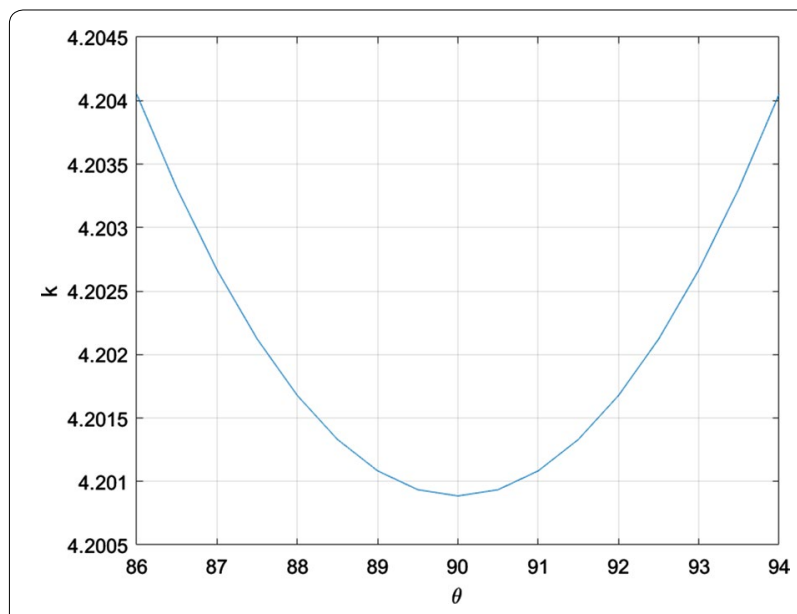

Fig. 7 Values of $k$



Fig. 8 Initial gravity anomaly derived from $\mathrm{HY}-2 \mathrm{~A}$

Table 4 Comparing initial HY-2A-derived gravity anomalies with other models (unit: $\mathrm{mGal}$ )

\begin{tabular}{lllll}
\hline Model difference & Minimum & Maximum & Mean & Std \\
\hline HY-2A-SIO & -24.951 & 26.242 & 0.843 & 7.259 \\
HY-2A-DTU13 & -25.896 & 27.951 & 0.670 & 7.084 \\
HY-2A-EGM2008 & -27.075 & 27.434 & 0.696 & 7.087 \\
HY-2A-EIGEN-6C4 & -27.364 & 25.513 & 0.658 & 7.186 \\
\hline
\end{tabular}

EGM2008 and EIGEN-6C4 are close to each other. This means SIO, DTU13, EGM2008 and EIGEN-6C4 have closely the same accuracy. The magnitudes of the minimum and maximum differences all exceed 25 $\mathrm{mGal}$. The mean values of the differences all exceed $0.6 \mathrm{mGal}$. This means some systematic errors exist in the derived gravity anomalies. The standard deviations of the differences are all smaller than $7.5 \mathrm{mGal}$ which arrives at the marine detection objectives of HY-2A, i.e., $10 \mathrm{mGal}$. 
According to Small and Sandwell (1992) and Hwang and Parsons (1996), the residual gravity anomaly can also be derived by either $\Delta \varepsilon$ or $\Delta \eta$, i.e.,



Considering the different precisions of $\varepsilon$ or $\eta$, Hwang and Parsons (1996) proposed an optimal method to combine them to improve the accuracy of the final gravity anomaly products. According to the analysis of the deflections of the vertical, the east component of vertical deflections has a poorer accuracy compared to the north component. The method, similar to Hwang and Parsons (1996) was experimented here to further improve the accuracy of the derived gravity anomalies, i.e., by giving different weights to $\delta g_{\varepsilon}$ and $\delta g_{\eta}$ to obtain a new version of gravity anomalies. In order to find the optimal weights, the following extreme problem was constructed:

$$
\left\{\begin{array}{l}
\delta g=a \delta g_{\varepsilon}+b \delta g_{\eta} \\
a+b=1 \\
f_{\min }=\min \left(a^{2} \delta_{\delta_{g_{\varepsilon}}}^{2}+b^{2} \delta_{\delta_{g_{\eta}}}^{2}+2 a b \delta_{\delta_{g_{\varepsilon}} \delta_{g_{\eta}}}^{2}\right)
\end{array},\right.
$$

where $a$ and $b$ are the combination parameters to derive the new gravity anomalies; $\delta_{\delta_{g \varepsilon}}^{2}, \delta_{\delta_{\eta}}^{2}$ are the error variances of $\delta g_{\varepsilon}$ and $\delta g_{\eta} ; \delta_{\delta_{g_{\varepsilon}} \delta_{g_{\eta}}}^{2}$ is the co-variances between $\delta g_{\varepsilon}$ and $\delta g_{\eta}$. If $\delta_{\delta_{g_{\varepsilon}}}^{2}, \delta_{\delta_{g_{\eta}}}^{2}$ and $\delta_{\delta_{g_{\varepsilon}} \delta_{g_{\eta}}}^{2}$ are known, the solution of Eq. (13) is:

$$
\left\{\begin{array}{l}
a=\frac{\delta_{\delta_{g_{\eta}}}^{2}-\delta_{\delta_{g_{\varepsilon}} \delta_{g_{\eta}}}^{2}}{\delta_{\delta_{g_{\varepsilon}}}^{2}+\delta_{\delta_{g_{\eta}}}^{2}-2 \delta_{\delta_{\varepsilon}}^{2} \delta_{g_{\eta}}} \\
b=\frac{\delta_{\delta_{g_{\varepsilon}}}^{2}-\delta_{\delta_{g_{\varepsilon}} \delta_{g_{\eta}}}^{2}}{\delta_{\delta_{g_{\varepsilon}}}^{2}+\delta_{\delta_{g_{\eta}}}^{2}-2 \delta_{\delta_{g_{\varepsilon}} \delta_{g_{\eta}}}^{2}}
\end{array}\right.
$$

It needs to be noted that the utmost concern is the relative values of $\delta_{\delta_{g \varepsilon}}^{2}, \delta_{\delta_{g_{\eta}}}^{2}$ and $\delta_{\delta_{\varepsilon} \delta_{g \eta}}^{2}$, but not their absolute values. Since their values are mainly decided by the accuracy of HY-2A vertical deflections, $a$ and $b$ are derived using variance and co-variances of vertical deflections instead, i.e.,

Table 5 Statistics about the variances and co-variances of vertical deflection errors

\begin{tabular}{lllcr}
\hline & Component & $\begin{array}{l}\text { HY-2A- } \\
\text { EGM2008 }\end{array}$ & $\begin{array}{l}\text { HY-2A- } \\
\text { EIGEN-6C4 }\end{array}$ & Mean \\
\hline Variance & $\delta_{\Delta \varepsilon}^{2}$ & 1.208 & 1.219 & 1.214 \\
& $\delta_{\Delta \eta}^{2}$ & 20.868 & 20.873 & 20.870 \\
\multirow{2}{*}{ Co-variances } & $\delta_{\Delta \varepsilon \Delta \eta}^{2}$ & 0.038 & 0.041 & 0.039 \\
\hline
\end{tabular}

$$
\left\{\begin{array}{l}
a=\frac{\delta_{\Delta \eta}^{2}-\delta_{\Delta \varepsilon \Delta \eta}^{2}}{\delta_{\Delta \varepsilon}^{2}+\delta_{\Delta \eta}^{2}-2 \delta_{\Delta \varepsilon \Delta \eta}^{2}} \\
b=\frac{\delta_{\Delta \varepsilon}^{2}-\delta_{\Delta \varepsilon \eta}^{2}}{\delta_{\Delta \varepsilon}^{2}+\delta_{\Delta \eta}^{2}-2 \delta_{\Delta \varepsilon \Delta \eta}^{2}}
\end{array}\right.
$$

$\delta_{\Delta \varepsilon}^{2} \delta_{\Delta \eta}^{2}$ are the error variances of $\Delta \varepsilon$ and $\Delta \eta ; \delta_{\Delta \varepsilon \Delta \eta}^{2}$ is the co-variances between $\Delta \varepsilon$ and $\Delta \eta$. In order to derive $a$ and $b$, the vertical deflections from 2160 degrees and orders of EGM2008 and EIGEN-6C4 are seen as the true values and thus $\delta_{\Delta \varepsilon}^{2}, \delta_{\Delta \eta}^{2}$ can be derived by the results of Table 3. The statistics about the variances and co-variances are given in Table 5 .

Hence, $a=0.947$ and $b=0.053$. Using these parameters, an improved new version of gravity anomalies (Fig. 9) in the study area are derived. The comparison between the new and initial HY-2A gravity anomalies is summarized in Table 6. It also shows that the new version has a greater range of gravity anomalies. The difference between the new gravity anomalies and DTU13, SIOv28, EGM2008 and EIGEN-6C4 gravity anomalies are given in Table 7. Figure 10 is a perspective view of these differences. The similarities in the constituents of Fig. 10 validate the statistics contained in Table 7. Further analysis of these comparisons revealed that on average, a significant $83-95 \%$ of the HY-2A data yielded gravity anomaly differences around 2.0-3.5 mGal as seen in Fig. 11. Obviously, these differences are mainly caused by the SSH observation noises. With more observations, the differences would be reduced further in future.

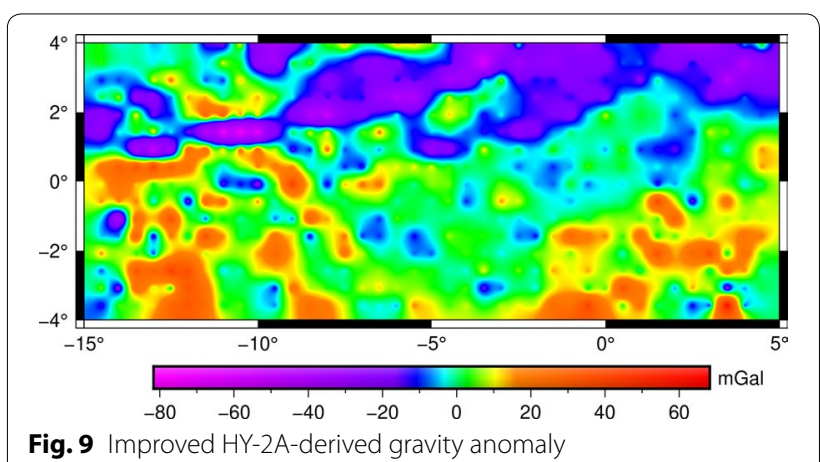

Table 6 Comparing the initial and improved versions of HY-2A-derived gravity anomalies (unit: $\mathrm{mGal}$ )

\begin{tabular}{lllrr}
\hline Model & Minimum & Maximum & Mean & \multicolumn{1}{c}{ Std } \\
\hline Initial HY-2A & -77.313 & 57.173 & 0.402 & 17.746 \\
Improved HY-2A & -81.696 & 68.261 & -0.655 & 16.953 \\
Improved HY-2A- & -17.979 & 16.509 & -0.821 & 5.863 \\
\begin{tabular}{l} 
initial HY-2A \\
\hline
\end{tabular} & & & & \\
\hline
\end{tabular}


Table 7 Comparing new version of HY-2A-derived gravity anomalies with other models (unit: $\mathrm{mGal}$ )

\begin{tabular}{lccrc}
\hline Model difference & Minimum & Maximum & \multicolumn{1}{c}{ Mean } & \multicolumn{1}{c}{ Std } \\
\hline HY-2A-SIO & -11.618 & 10.754 & 0.162 & 3.040 \\
HY-2A-DTU13 & -10.906 & 10.195 & 0.015 & 2.697 \\
HY-2A-EGM2008 & -10.926 & 9.504 & 0.023 & 2.962 \\
HY-2A-EIGEN-6C4 & -10.805 & 10.712 & -0.011 & 2.932 \\
\hline
\end{tabular}

Definitely, compared with Table 4, the accuracy of the new version of gravity anomalies is improved largely. According to Table 7, the mean differences are close to zero which indicate no systematic errors exist as the results of Table 4 . In terms of std, the accuracy is also improved largely, by about more than two times. All these improvements indicate that the main errors of the initial HY-2A-derived gravity anomalies are created by the east component of vertical deflections. These results also prove that the accuracy of the HY-2A-derived gravity anomalies can be improved by assigning a smaller weight to the east component of vertical deflections and a bigger weight to the north component.

\section{Bathymetry inversion}

To further assess the reliability and geophysical capabilities of the HY-2A-derived gravity anomalies, they are used to invert the bathymetry of the study region using gravity-geologic method (GGM). The GGM was developed by Ibrahim and Hinze (Ibrahim and Hinze 1972) to map out elevations hidden by glacial drift deposits. It is a technique that combines satellite altimeter-derived gravity anomalies with sparse shipborne depths to predict reliable models of bathymetry (Hsiao et al. 2016; Xiang et al 2017; Kim and Yun 2018; Yeu et al. 2018). GGM uses the difference between the density of seawater $(1030 \mathrm{~kg} /$ $\mathrm{m}^{3}$ ) and density of ocean bedrock $\left(2700 \mathrm{~kg} / \mathrm{m}^{3}\right)$ to establish a relationship between the short-wavelength of gravity anomaly and depth (Xiang et al 2017). Recent studies such as: Kim et al. (2011), Xiang et al. (2017) and Yeu et al. (2018) have shown that though the use of a density contrast of $1670 \mathrm{~kg} / \mathrm{m}^{3}$ yields good results, the use of the socalled iterative density contrast produces better results. The iterative density contrast chooses an optimal density contrast among a range of values that minimizes the root mean square error of the observed shipborne depth and its corresponding predicted bathymetry. It must be appreciated that this density contrast has more analytical meaning. This is because such optimal density contrast is usually greater than the physically meaningful value of $1670 \mathrm{~kg} / \mathrm{m}^{3}$. Therefore, the present study applies the iterative density contrast in the GGM implementation.

Shipborne depths were obtained from the National Geophysical Data Center of the National Oceanic and

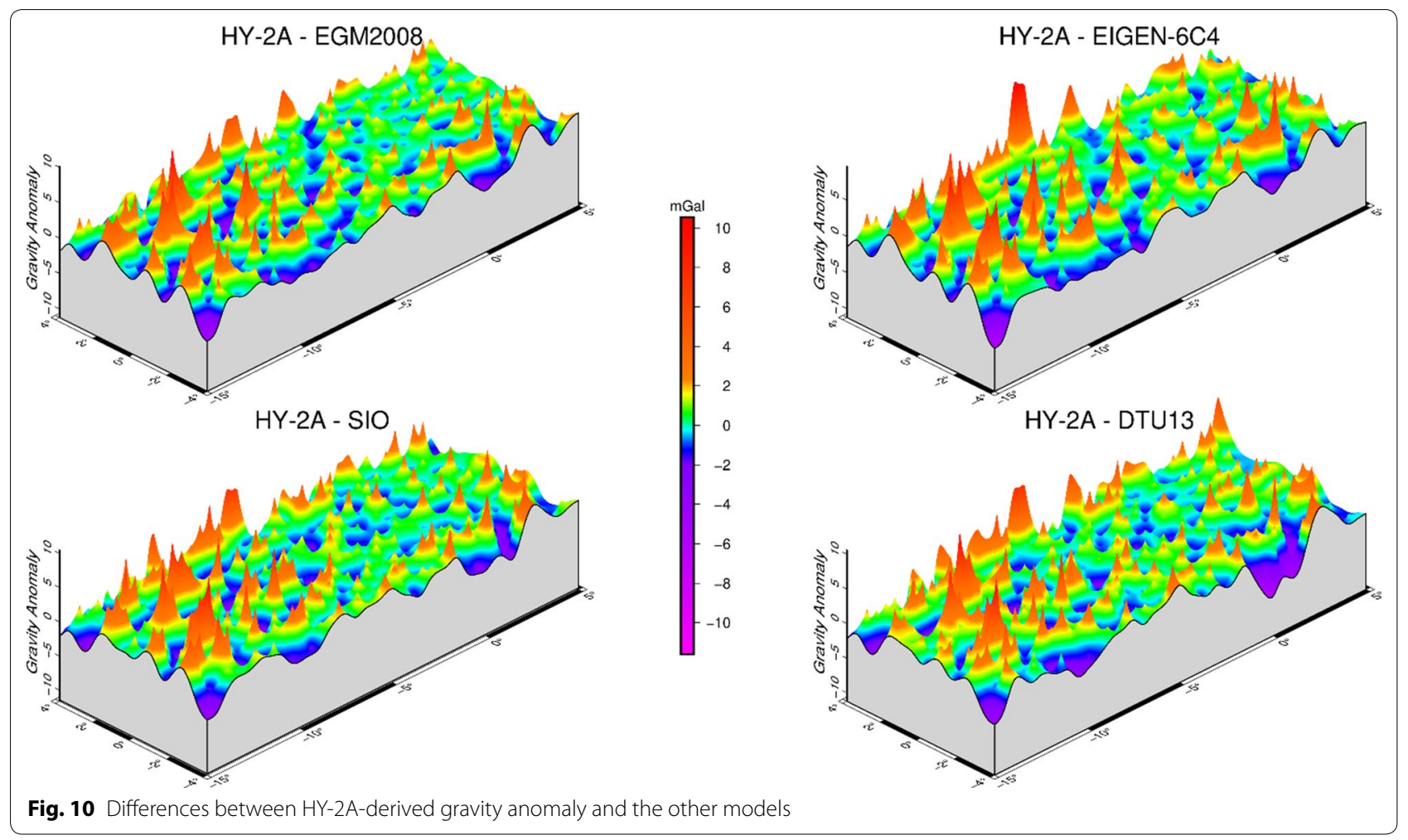




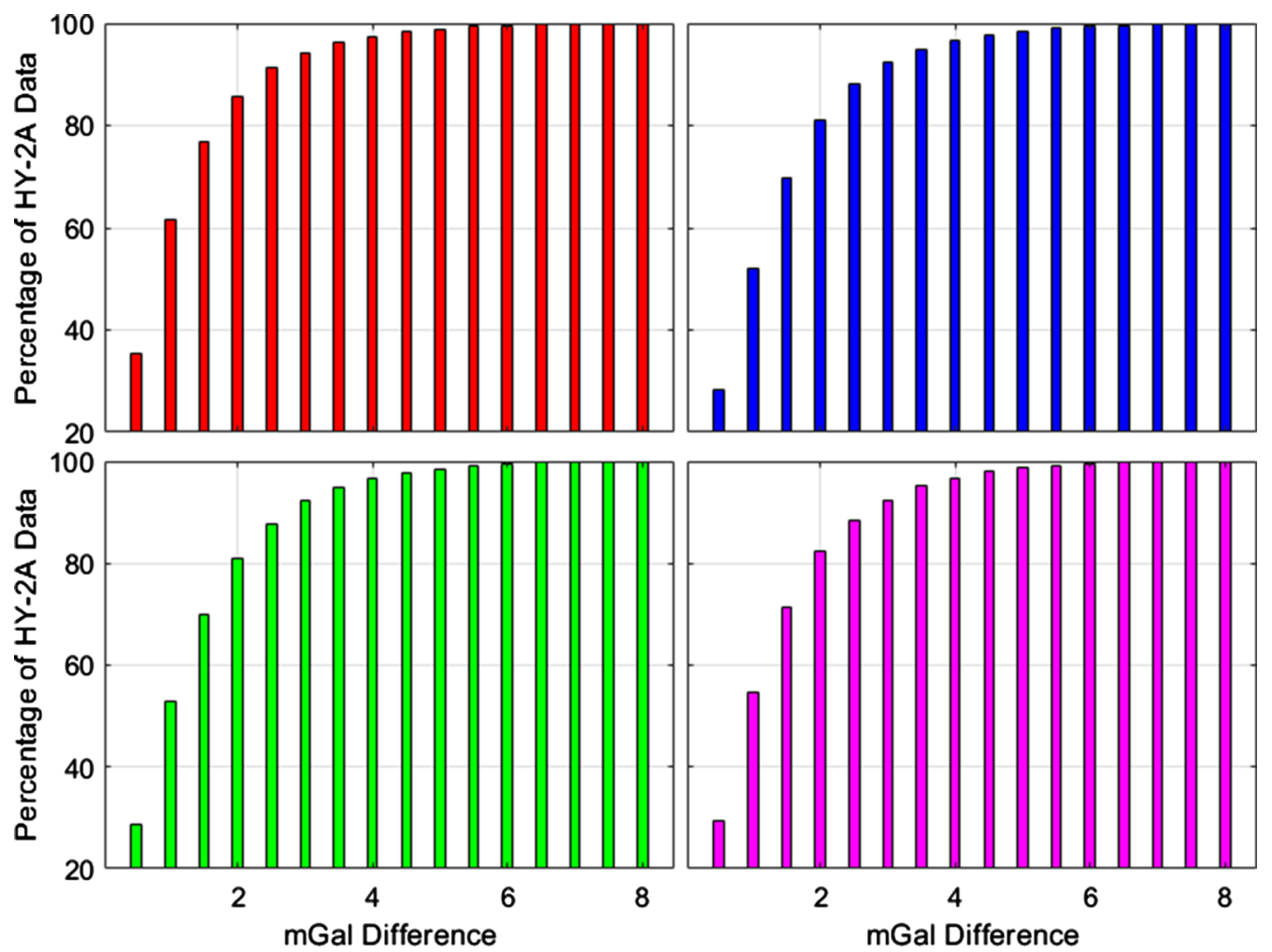

Fig. 11 Percentage evaluation of HY-2A data in gravity anomaly accuracy achievement

Atmospheric Administration. They were randomly divided into $75 \%$ control and $25 \%$ test points. The gravity anomalies, $\Delta g(i)$, were decomposed into long-wavelength, $\Delta g_{1}(i)$, and short-wavelength, $\Delta g_{\mathrm{s}}(i)$. This is given by:

$$
\Delta g(i)=\Delta g_{s}(i)+\Delta g_{l}(i)
$$

At each control point $i$, the short-wavelength gravity anomaly, $\Delta g_{\mathrm{s}}(i)$, is related to depth, $E(i)$, by:

$$
\Delta g_{\mathrm{s}}(i)=2 \pi G \Delta \rho(E(i)-D),
$$

where $\Delta \rho$ is density contrast; $G=6.67 \times 10^{-11} \mathrm{~N} \mathrm{~m}^{2} / \mathrm{kg}^{2}$, is the gravitational constant; and $D$ is the deepest depth.

The long-wavelength gravity anomalies, $\Delta g_{1}(i)$, at control point $i$, were obtained by subtracting the shortwavelength gravity anomalies, $\Delta g_{\mathrm{s}}(i)$, from the observed gravity anomalies, $\Delta g(i)$. These $\Delta g_{1}(i)$ values were then gridded to interpolate for the long-wavelength gravity anomalies, $\Delta g_{1}(j)$, of uncharted points, $j$. The values of $\Delta g_{1}(j)$ were subsequently removed from their corresponding $\Delta g(j)$ to obtain short-wavelength gravity anomalies, $\Delta g_{\mathrm{s}}(j)$, of uncharted points. By making $E(j)$ the subject of Eq. (17), the elevations of uncharted points, $j$, above the datum are computed by:

$$
E(j)=\frac{\Delta g_{\mathrm{s}}(j)}{2 \pi G \Delta \rho}+D
$$

Using an optimal density contrast of $7500 \mathrm{~kg} / \mathrm{m}^{3}$, the bathymetry (see Fig. 12) of the study area was finally predicted using the HY-2A-derived gravity anomalies. The predicted bathymetry was assessed by comparing it with the ETOPO1 (Earth Topographical Database 1) (Amante and Eakins 2009) and SRTM15 + V2.0 (Shuttle Radar Topography Mission 15_Plus Version 2) models (Tozer et al. 2019). The summary statistics of the three bathymetric models is presented in Table 8 . Table 9 shows the performance of the HY-2A-derived bathymetric model expressed in terms of mean and standard deviation of its differences between and shipborne depths, ETOPO1 and SRTM15+V2; as well as its correlation coefficients with these reference models at $0.9568,0.9562$ and 0.9590 , respectively. Figure 13 presents a pictorial view of the reference models, as well as their differences with respect to the HY2A-derived bathymetry. According to this figure, the HY-2A-derived bathymetry differs slightly from shipborne-depths, SRTM15+ V2, and ETOPO1 except in south-eastern corner of the study area. 


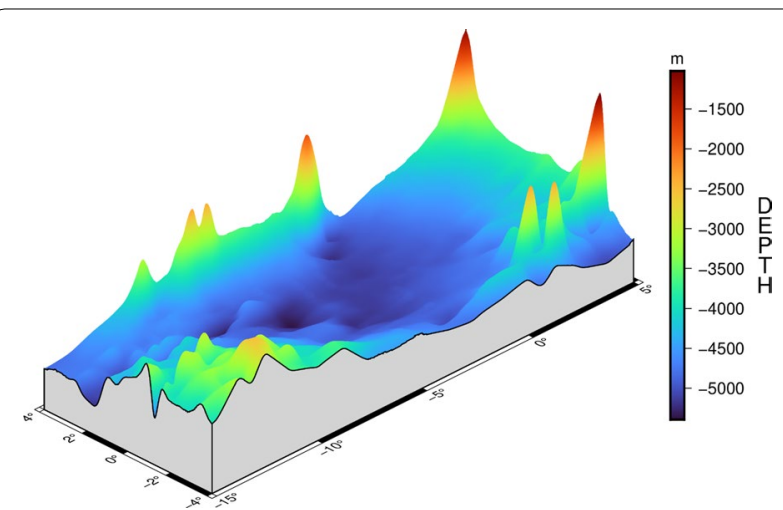

Fig. 12 Bathymetry of study area predicted by HY-2A-derived gravity anomaly

Table 8 Statistics of bathymetry models from HY-2A, ETOPO1 and SRTM15 + (unit: $\mathrm{m}$ )

\begin{tabular}{lllll}
\hline Bathymetric model & Minimum & Maximum & Mean & Std \\
\hline HY-2A & -5912.00 & -86.00 & -4456.09 & 584.94 \\
ETOPO1 & -5912.00 & -86.00 & -4466.47 & 582.38 \\
SRTM15+ & -5722.54 & -8.04 & -4468.65 & 574.90 \\
\hline
\end{tabular}

Table 9 Performance of HY-2A-derived bathymetry

\begin{tabular}{lccl}
\hline Bathymetric difference & Mean $(\mathbf{m})$ & Std $(\mathbf{m})$ & Corr. coefficient \\
\hline HY-2A-ETOPO1 & 26.67 & 185.09 & 0.9562 \\
HY-2A-SRTM15+ & 12.26 & 174.55 & 0.9590 \\
HY-2A-Ship & -9.78 & 185.69 & 0.9568 \\
ETOPO1-Ship & 16.41 & 114.18 & 0.9826 \\
SRTM15+-Ship & -1.26 & 25.86 & 0.9976 \\
\hline
\end{tabular}

\section{Discussion}

The HY-2A-derived bathymetry generally compares well with a previous study of the study area by the authors (Annan and Wan 2020) that used DTU13 gravity anomalies. In Annan and Wan (2020), the overall standard deviation of differences between the inverted model and ship depths was $184.74 \mathrm{~m}$, whereas it is $185.69 \mathrm{~m}$ in this study. The bathymetric model in this study also generally depicts the rugged topography at the southern corners of the study area, as well as the fairly gentle terrain at the center. The observed large discrepancies in bathymetric differences (see Fig. 13) at the south-eastern part of the study region is as a result of the sparseness of shipborne depth coupled with shallow waters. Similar observations were made in Annan and Wan (2020). Therefore, it can be concluded that the accuracy of the study region's bathymetry through GGM could be improved if shipborne depths in this subregion can be densified.

The objective of the present study is to assess the HY-2A observations in the study area; therefore, data from other satellites were not considered. However, it is expected that the inclusion of SSH data from other modern satellites such as SARAL/AltiKa and the interferometric altimeter satellite Cryosat-2, can improve the results of marine gravity fields recoveries and/or bathymetry estimations. These two satellites have good spatial resolution. Also, it is expected that future SSH data from the SWOT (Surface Water and Ocean Topography) mission to be launched in September 2021, will contribute significantly to this topic. In addition, the reference model can be replaced by a more recent model such as XGM2019e (Zingerle et al. 2020), which may also improve the accuracy of the derived gravity anomalies in the study area.

In summary, the reliability of HY-2A has been assessed in another environment with significant mass variations apart from the South China Sea, where almost all its previous regional evaluations have been carried out. This indicates that the SSH data from HY-2A are reliable and are geophysically capable. Therefore, they can be incorporated with data from other satellite altimeters for geodetic, geophysical and oceanographic applications.

\section{Conclusion}

The performance of HY-2A/GM observations for deriving marine gravity field products in the Gulf of Guinea was studied in this paper. The results show that the HY2A-derived gravity anomalies have a precision higher than $7.5 \mathrm{mGal}$ in the study area. The numerical analysis shows that the east component of the vertical deflections has a poorer precision than the north component, which has also been proven by theoretical analysis according to the error propagation rule. By giving a smaller weight to the east component of the vertical deflections, the precision of the newly derived gravity anomalies was improved largely. This means it is key to improve the precision of east component of vertical deflections in order to obtain highly accurate marine gravity field products. One possible method is to combine other altimetry satellite observations, especially those observations provided by altimetry satellites with non-polar orbits, such as Topex. A bathymetric model predicted by the improved HY-2A-derived gravity anomalies yielded comparable results with a previous study (Annan and Wan 2020) of the region by the authors. The modeled bathymetry also compared well with ETOPO1 (with resolution of 1 arcminute) and SRTM15+V2 (with resolution of 15 arc-seconds). This proves that $\mathrm{SSH}$ data from HY-2A are capable 

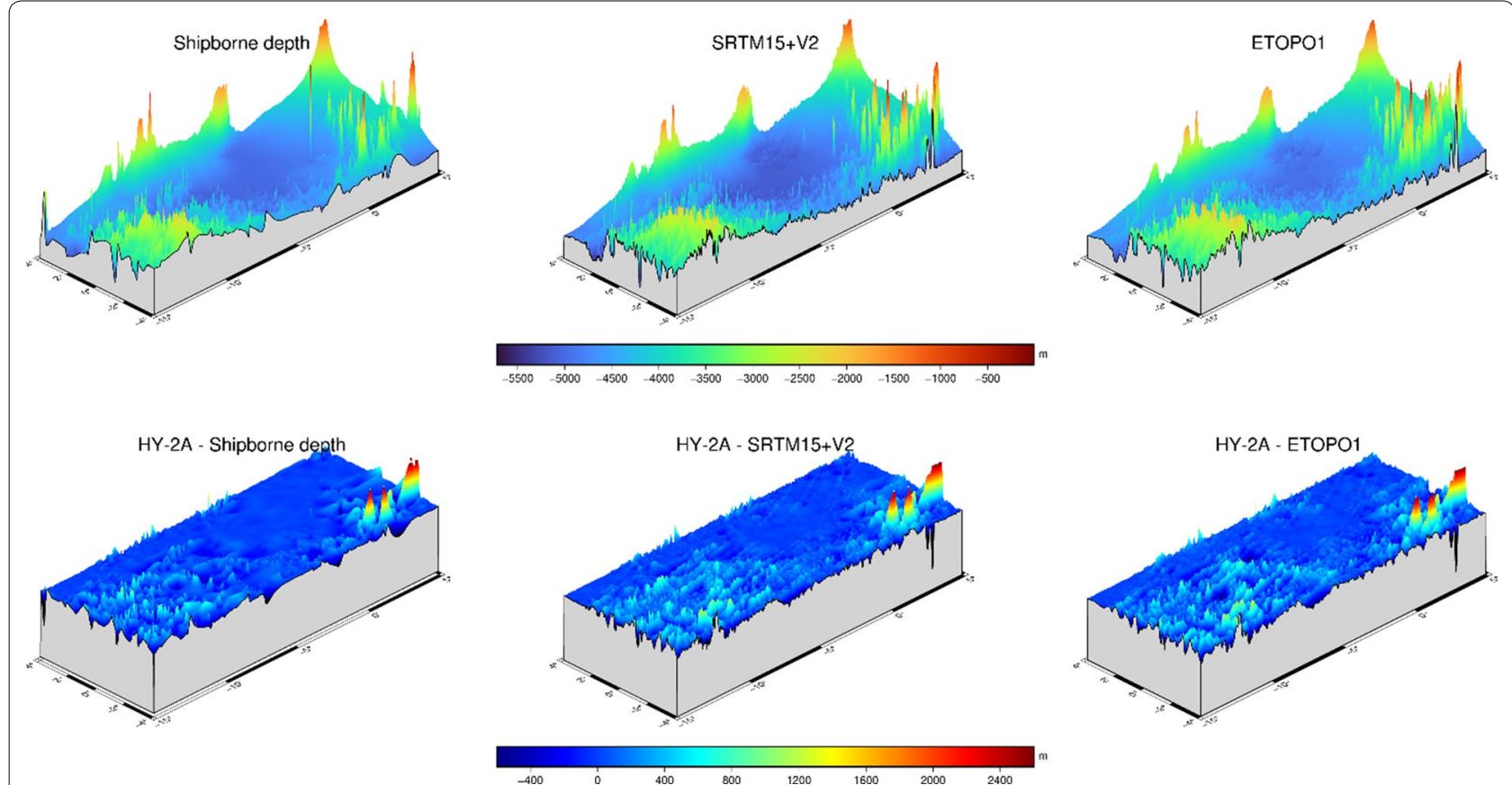

Fig. 13 HY-2A-derived bathymetry as compared with other bathymetric models

for geodetic, geophysical and oceanographic applications. Indeed, the Chinese government is designing and developing HY-2A follow-on satellites (Pang and Wang 2016). HY-2B has been launched in 2018 and HY-2C would be launched in the near future. HY-2C is designed with an inclined-orbit, which would be very beneficial to improve the precisions of the east component of vertical deflections as well as the gravity anomalies products.

\section{Abbreviations}

HY-2A: Haiyang-2A; GM: Geodetic mission; IGDR: Interim geophysical data record; SIO: Scripps Institution of Oceanography; DTU13, 18: Technical University of Denmark 2013, 2018; EGM2008: Earth Geopotential Model 2008; EIGEN6C4: Fourth release of European Improved Gravity model of the Earth by New techniques 6C; NASA: National Aeronautics and Space Administration; SSH: Sea surface height; ERS: European Space Agency; ENVISAT: Environmental Satellite; FFT: Fast Fourier transform; LSC: Least squares collocation; GMT: Generic Mapping Tools; CLS15: Collecte Localisation Satellites 2015; CNES: Centre National d'Etudes Spatiales; AVISO: Archiving, Validation and Interpretation of Satellite Oceanographic data; GGM: Gravity-geologic method; ETOPO1: Earth Topographical Database 1; SRTM15 + V2: Shuttle Radar Topography Mission 15_Plus Version 2; XGM2019e: Experimental Geopotential Model 2019; Cryosat-2: Cryosphere Satellite 2; SARAL/AltiKa: Satellite with ARgos and ALtiKa; SWOT: Surface Water and Ocean Topography.

\section{Acknowledgements}

The authors would like to thank the National Satellite Ocean Application Service of China for providing HY-2A data. We are grateful to DTU for providing DTU13 and DTU18, as well as SIO for providing SIOv28 and SRTM15+V2. Also, we are very appreciative to AVISO for providing CLS15. The maps in this study were drawn using GMT (Generic Mapping Tools). We acknowledge the use of shipborne depth data from the National Geophysical Data Center of the National Oceanic and Atmospheric Administration.

\section{Authors' contributions}

Conceptualization and investigation: XW and RFA; data curation and methodology: XW, RFA and WW; funding: XW and WW; writing —original draft: XW and RFA; writing — review and editing: all the authors. All authors read and approved the final manuscript.

\section{Funding}

This research was funded by the National Natural Science Foundation of China (Nos. 41674026, 42074017); Fundamental Research Funds for the Central Universities (No. 2652018027); China Geological Survey (No. 20191006); Open Research Fund of Key Laboratory of Space Utilization, Chinese Academy of Sciences (LSU-KFJJ-201902); Qian Xuesen Lab._-DFH Sat. Co. Joint Research and Development Fund under grants (M-2017-006).

\section{Availability of data and materials}

The data used in this study is available from the National Satellite Ocean Administration Service of China (ftp2.nsoas.org.cn).

\section{Ethics approval and consent to participate}

Not applicable.

\section{Consent for publication}

Not applicable.

\section{Competing interests}

The authors declare that they have no competing interests.

\section{Author details}

${ }^{1}$ School of Land Science and Technology, China University of Geosciences (Beijing), Beijing 100083, China. ${ }^{2}$ Key Laboratory of Space Utilization, Technology and Engineering Center for Space Utilization, Chinese Academy of Sciences, Beijing 100094, China.

Received: 31 July 2020 Accepted: 6 October 2020

Published online: 17 October 2020 


\section{References}

Amante C, Eakins BW (2009) ETOPO1 1 Arc-minute global relief model: procedures, data sources and analysis. NOAA Technical Memorandum NESDIS NGDC-24

Andersen OB, Knudsen P (1998) Global marine gravity field from the ERS-1 and Geosat geodetic mission altimetry. J Geophys Res 103:8129-8137

Andersen OB, Knudsen P (2019) The DTU17 global marine gravity field: first validation results. In: Mertikas S, Pail R (eds) Fiducial Reference Measurements for Altimetry, International Association of Geodesy Symposia, 150, Springer, Cham. https://doi.org/10.1007/1345_2019_65

Andersen OB, Knudsen P, Berry P (2010) The DNSC08GRA global marine gravity field from double retracked satellite altimetry. J Geod. https://doi. org/10.1007/s00190-009-0355-9

Annan RF, Wan X (2020) Mapping seafloor topography of Gulf of Guinea using an adaptive meshed gravity-geologic method. Arab J Geosci 13:301. https://doi.org/10.1007/s12517-020-05297-8

Becker JJ et al (2009) Global bathymetry and elevation data at 30 arc seconds resolution: SRTM30 PLUS. Mar Geod 32:355-371

Chander S, Majumdar TJ (2016) Comparison of SARAL and Jason-1/2 altimetryderived geoids for geophysical exploration over the Indian offshore. Geocarto Int 31(2):158-175. https://doi.org/10.1080/10106049.2015.1041562

Chen C, Zhu J, Zhai W, Yan L, Zhao Y, Huang X, Yang W (2019) Absolute calibration of HY-2A and Jason-2 altimeters for sea surface height using GPS buoy in Qinglan, China. J Oceanol Limnol 37(5):1533-1541

Dadzie I, Li J, Chu Y (2008) Prediction of Gravity Anomalies over the South China and Philippine Seas from Multi-satellite Altimeter Sea Surface Heights. Geo-Spatial Inf Sci 11(3):174-179

Hsiao T-S et al (2016) High-resolution depth and coastline over major atolls of South China Sea from satellite altimetry and imagery. Remote Sens Environ 176:69-83

Hwang C (1998) Inverse Vening Meinesz formula and deflection-geoid formula: applications to the predictions of gravity and geoid over the South China Sea. J Geod 72:304-312

Hwang C, Chang ETY (2014) Seafloor secrets revealed. Science 346:32. https:// doi.org/10.1126/science.1260459

Hwang C, Parsons B (1996) An optimal procedure for deriving marine gravity from multi-satellite altimetry. Geophys J Int 125(3):705-718

Ibrahim A, Hinze WJ (1972) Mapping buried bedrock topography with gravity. Ground Water 10(3):18-23

Jiang M, Xu K, Xiong Y (2018) First Assessment of HY-2A Altimeter data over Antarctica and Greenland using crossover analysis. In: 2018 IEEE international geoscience and remote sensing symposium (IGARSS). IEEE

Kim JW, von Frese RRB, Lee BY, Roman DR, Doh SJ (2011) Altimetry-derived gravity predictions of bathymetry by gravity-geologic method. Pure Appl Geophys 168:815-826

Kim KB, Yun HS (2018) Satellite-derived bathymetry prediction in shallow waters using the gravity-geologic method: a case study in the West Sea of Korea. KSCE J Civ Eng 22(7):2560-2568

Olgiati A, Balmino G, Sarrailh M, Green CM (1995) Gravity anomalies from satellite altimetry: comparison between computation via geoid heights and via deflections of the vertical. Bull Géodésique 69(4):252-260

Osaretin I (2011) Energy security in the Gulf of Guinea and the challenges of the great powers. J Soc Sci 27(3):187-191

Pang D, Wang T (2016) HY-2B and HY-2C operational satellites under development. Aerospace China 17(01):69

Sandwell D, Smith W (1997) Marine gravity anomaly from Geosat and ERS1 satellite altimetry. J Geophys Res 102:10039-10054

Sandwell DT, Smith, WHF, Gille S, Jayne S, Soofi K, Coakley B (2001) Bathymetry from space: White paper in support of a high-resolution, ocean altimeter mission. In: Proceedings of high-resolution ocean topography science working group meeting, CEOAS, April 5

Sandwell DT, Gracia E, Soofi K, Wessel P, Chandler M, Smith WHF (2013) Toward 1 -mGal accuracy in global marine gravity from Cryost-2, Envisat and Jason-1. Lead Edge 32(8):892-899

Sandwell D, Dietmar Muller R, Smith WHF, Garcia E, Francis R (2014) New global marine gravity model from CryoSat-2 and Jason-1 reveals buried tectonic structure. Science 346(6205):65-67

Sandwell DT, Harper H, Tozer B, Smith WHF (2019) Gravity field recovery from geodetic altimeter missions. Adv Space Res. https://doi.org/10.1016/j. asr.2019.09.011

Small C, Sandwell D (1992) A comparison of satellite and shipboard gravity measurements in the Gulf of Mexico. Geophysics 57(7):885-893

Soltanpour A, Nahavandchi H, Ghazavi K (2007) Recovery of marine gravity anomalies from ERS1, ERS2 and Envisat satellite altimetry data for geoid computations over Norway. Stud Geophys Geod 51:369-389

Tozer B, Sandwell DT, Smith WHF, Olson C, Beale JR, Wessel P (2019) Global Bathymetry and Topography at 15 Arc Sec: SRTM15+. Earth Space Sci. https://doi.org/10.1029/2019EA000658

Weszkanys G (2011) Cursed resources, or articulations of economic theory in the Gulf of Guinea. Econ Soc 40(3):345-372

Xiang X, Wan X, Zhang R, Li Y, Sui X, Wang W (2017) Bathymetry inversion with the gravity-geologic method: a study of long wavelength gravity modeling based on adaptive mesh. Mar Geod 40(5):329-340

Yang L, Zhou XH, Lin MS, Lei N, Mu B, Zhu L (2016) Global statistical assessment of HY-2A altimeter IGDR data. Progr Geophys 31(2):629-636

Yeu Y, Yee J-J, Yun HS, Kim KB (2018) Evaluation of the accuracy of bathymetry on the Nearshore coastlines of Western Korea from satellite altimetry, multi-beam, and airborne bathymetric LiDAR. Sensors. https://doi. org/10.3390/s18092926

Zhang S (2017) Research on determination of marine gravity anomalies from multi-satellite altimeter data. Doctoral Thesis, Wuhan University

Zhang S, Sandwell D, Jin T, Li D (2016) Inversion of marine gravity anomalies over southeastern China seas from multi-satellite altimeter vertical deflections. J Appl Geophys. https://doi.org/10.1016/j.jappgeo

Zhang S, Andersen OB, Kong X, Li H (2020) Inversion and validation of improved marine gravity field recovery in South China Sea by incorporating HY-2A altimeter waveform data. Remote Sens 12(5):802. https://doi. org/10.3390/rs12050802

Zhu C, Guo J, Hwang C, Gao J, Yuan J, Liu X (2019) How HY-2A/GM altimeter performs in marine gravity derivation: assessment in the South China Sea. Geophys J Int 219(2):1056-1064. https://doi.org/10.1093/gji/ggz330

Zhu C, Guo J, Gao J, Hwang C, Yu S, Yuan J, Ji B, Guan B (2020) Marine gravity determined from multi-satellite GM/ERM altimeter data over the South China Sea: SCSGA V10. J Geodesy 94:50. https://doi.org/10.1007/s0019 0-020-01378-4

Zingerle P, Pail R, Gruber T, Oikonomidou X (2020) The combined global gravity field model XGM2019e. J Geod 94:66. https://doi.org/10.1007/s0019 0-020-01398-0

\section{Publisher's Note}

Springer Nature remains neutral with regard to jurisdictional claims in published maps and institutional affiliations. 